NASA/CR-2003-212384

\title{
Resonance Effects in the NASA Transonic Flutter Cascade Facility
}

J. Lepicovsky

QSS Group, Inc., Cleveland, Ohio

V.R. Capece and C.T. Ford

University of Kentucky, Paducah, Kentucky 
Since its founding, NASA has been dedicated to the advancement of aeronautics and space science. The NASA Scientific and Technical Information (STI) Program Office plays a key part in helping NASA maintain this important role.

The NASA STI Program Office is operated by Langley Research Center, the Lead Center for NASA's scientific and technical information. The NASA STI Program Office provides access to the NASA STI Database, the largest collection of aeronautical and space science STI in the world. The Program Office is also NASA's institutional mechanism for disseminating the results of its research and development activities. These results are published by NASA in the NASA STI Report Series, which includes the following report types:

- $\quad$ TECHNICAL PUBLICATION. Reports of completed research or a major significant phase of research that present the results of NASA programs and include extensive data or theoretical analysis. Includes compilations of significant scientific and technical data and information deemed to be of continuing reference value. NASA's counterpart of peerreviewed formal professional papers but has less stringent limitations on manuscript length and extent of graphic presentations.

- TECHNICAL MEMORANDUM. Scientific and technical findings that are preliminary or of specialized interest, e.g., quick release reports, working papers, and bibliographies that contain minimal annotation. Does not contain extensive analysis.

- CONTRACTOR REPORT. Scientific and technical findings by NASA-sponsored contractors and grantees.
- CONFERENCE PUBLICATION. Collected papers from scientific and technical conferences, symposia, seminars, or other meetings sponsored or cosponsored by NASA.

- SPECIAL PUBLICATION. Scientific, technical, or historical information from NASA programs, projects, and missions, often concerned with subjects having substantial public interest.

- TECHNICAL TRANSLATION. Englishlanguage translations of foreign scientific and technical material pertinent to NASA's mission.

Specialized services that complement the STI Program Office's diverse offerings include creating custom thesauri, building customized databases, organizing and publishing research results ... even providing videos.

For more information about the NASA STI Program Office, see the following:

- Access the NASA STI Program Home Page at http://www.sti.nasa.gov

- E-mail your question via the Internet to help@sti.nasa.gov

- Fax your question to the NASA Access Help Desk at 301-621-0134

- Telephone the NASA Access Help Desk at 301-621-0390

- Write to:

NASA Access Help Desk

NASA Center for AeroSpace Information 7121 Standard Drive

Hanover, MD 21076 
NASA/CR-2003-212384

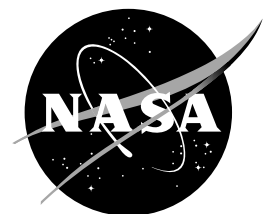

\section{Resonance Effects in the NASA Transonic Flutter Cascade Facility}

J. Lepicovsky

QSS Group, Inc., Cleveland, Ohio

V.R. Capece and C.T. Ford

University of Kentucky, Paducah, Kentucky

Prepared for the

Turbo Expo 2003

cosponsored by the American Society of Mechanical Engineers

and the International Gas Turbine Institute

Atlanta, Georgia, June 16-19, 2003

Prepared under Grant NAG3-2695

National Aeronautics and

Space Administration

Glenn Research Center 


\section{Acknowledgments}

The work was sponsored by the NASA Glenn Research Center under the Smart Engine Components Project managed by Mr. R.D. Corrigan as a part of the R\&T Base Propulsion and Power Program. The authors would like to thank Mrs. L. Shaw, Chief, GRC Compressor Branch, for her continuous support.

Significant help from Dr. E.R. McFarland, NASA GRC, is also gratefully acknowledged.

This report is a preprint of a paper intended for presentation at a conference. Because of changes that may be made before formal publication, this preprint is made available with the understanding that it will not be cited or reproduced without the permission of the author.

The Propulsion and Power Program at NASA Glenn Research Center sponsored this work.

Available from

NASA Center for Aerospace Information 7121 Standard Drive

Hanover, MD 21076
National Technical Information Service 5285 Port Royal Road Springfield, VA 22100 
GT-2003-38344

\title{
RESONANCE EFFECTS IN THE NASA TRANSONIC FLUTTER CASCADE FACILITY
}

\author{
J. Lepicovsky \\ QSS Group, Inc. \\ Cleveland, Ohio 44135 \\ V.R. Capece and C.T. Ford \\ University of Kentucky \\ Department of Mechanical Engineering \\ Paducah, Kentucky 42002
}

\section{ABSTRACT}

Investigations of unsteady pressure loadings on the blades of fans operating near the stall flutter boundary are carried out under simulated conditions in the NASA Transonic Flutter Cascade facility (TFC). It has been observed that for inlet Mach numbers of about 0.8 , the cascade flowfield exhibits intense low-frequency pressure oscillations. The origins of these oscillations were not clear. It was speculated that this behavior was either caused by instabilities in the blade separated flow zone or that it was a tunnel resonance phenomenon. It has now been determined that the strong lowfrequency oscillations, observed in the TFC facility, are not a cascade phenomenon contributing to blade flutter, but that they are solely caused by the tunnel resonance characteristics. Most likely, the self-induced oscillations originate in the system of exit duct resonators. For sure, the self-induced oscillations can be significantly suppressed for a narrow range of inlet Mach numbers by tuning one of the resonators. A considerable amount of flutter simulation data has been acquired in this facility to date, and therefore it is of interest to know how much this tunnel self-induced flow oscillation influences the experimental data at high subsonic Mach numbers since this facility is being used to simulate flutter in transonic fans. In short, can this body of experimental data still be used reliably to verify computer codes for blade flutter and blade life predictions? To answer this question a study on resonance effects in the NASA TFC facility was carried out. The results, based on spectral and ensemble averaging analysis of the cascade data, showed that the interaction between self-induced oscillations and forced blade motion oscillations is very weak and can generally be neglected. The forced motion data acquired with the mistuned tunnel, when strong self-induced oscillations were present, can be used as reliable forced pressure fluctuations provided that they are extracted from raw data sets by an ensemble averaging procedure.

\section{NOMENCLATURE}

$\begin{array}{lll}C & {[\mathrm{~mm}]} & \text { blade chord }(89.2 \mathrm{~mm}) \\ f & {[\mathrm{~Hz}]} & \text { frequency } \\ f_{\mathrm{B}} & {[\mathrm{Hz}]} & \text { frequency of forced blade oscillations } \\ k & {[1]} & \text { reduced frequency }\{(2 \pi \mathrm{fC} / 2) / \mathrm{v}\} \\ \boldsymbol{i}_{\mathrm{GM}} & {[\mathrm{dg}]} & \text { geometry incidence } \\ \mathrm{Ma} I \mathrm{IN} & {[\mathrm{l}]} & \text { cascade inlet Mach number } \\ p & {[\mathrm{kPa}]} & \text { static pressure } \\ p_{A} & {[\mathrm{kPa}]} & \text { pressure amplitude } \\ p_{D} & {[\mathrm{kPa}]} & \text { dynamic pressure } \\ p_{F} & {[\mathrm{kPa}]} & \text { pressure fluctuations (deviations from mean) } \\ p_{U} & {[\%]} & \text { pressure unsteadiness }\left(p_{\sigma} / p_{D}\right) \\ p_{\sigma} & {[\mathrm{kPa}]} & \text { pressure RMS value } \\ R 1_{L} & {[\mathrm{~mm}]} & \text { resonator cavity length } \\ t & {[\mathrm{~ms}]} & \text { time } \\ U & {[\mathrm{~V}]} & \text { signal voltage } \\ V & {[\mathrm{~m} / \mathrm{s}]} & \text { flow velocity } \\ \alpha_{B} & {[\mathrm{dg}]} & \text { blade oscillation amplitude } \\ \tau & {[\mathrm{l}]} & \text { dimensionless time of oscillation period } \\ \text { FFT } & \text { fast Fourier transform } \\ \text { RMS } & \text { root mean square } \\ \text { TFC } & \text { transonic flutter cascade }\end{array}$

\section{INTRODUCTION}

An extensive study into the nature of unsteady flow behavior about an airfoil section used in the tip region of modern, low-aspect ratio transonic fans is being conducted at the NASA Glenn Research Center (GRC). The main focus is on investigating unsteady pressure loading on the blades for fans operating near the stall flutter boundary. The results of these investigations have been reported regularly over several years (Refs. 1 through 6). 
The blade-tip cross-section profile of a modern transonic fan differs significantly from the rest of the fan blade. At design conditions, a fan blade tip section operates at supersonic relative velocities. Therefore, the tip section airfoils are designed for precompression, with a concave suction surface just downstream of the leading edge, and with little overall camber. The airfoils have a sharp leading edge that makes them prone to flow separation at off-design conditions. If an engine is forced to operate near fan stall conditions, the blade tip section is subjected to severe off-design flow with high incidence angles and high subsonic or transonic relative Mach numbers. These conditions result in blade stall flutter and associated high cycle fatigue problems that are detrimental to blade structural integrity and blade life. Blade flutter codes that account for stall flutter effects are not yet fully reliable; their verification is hampered by a lack of reliable unsteady aerodynamic loading data, particularly for airfoils with precompression. Interest in fan-blade stall-flutter research has increased in recent years.

Typically subsonic/transonic stall flutter occurs in the blade first torsion mode, because the airfoil unsteady aerodynamic loading is such that the blade can absorb energy during a cycle of oscillation for this type of blade motion. A critical parameter to judge a blade's susceptibility to flutter is reduced frequency, $k$. The reduced frequency is a ratio of particle convection time and oscillation period (Strouhal number). Blades with low reduced frequency are more prone to flutter. The combination of the unsteady loading distribution and the reduced frequency along with the steady operating conditions is what make modern fan blades susceptible to instability.

\section{NASA TRANSONIC FLUTTER CASCADE FACILITY}

For the last several years, the NASA GRC Transonic Flutter Cascade (TFC) facility has been used to investigate the unsteady aerodynamic loading of fan blades under simulated stall flutter conditions. The facility has been described in detail in Refs. 3 and 7 through 9. The facility is a linear cascade of

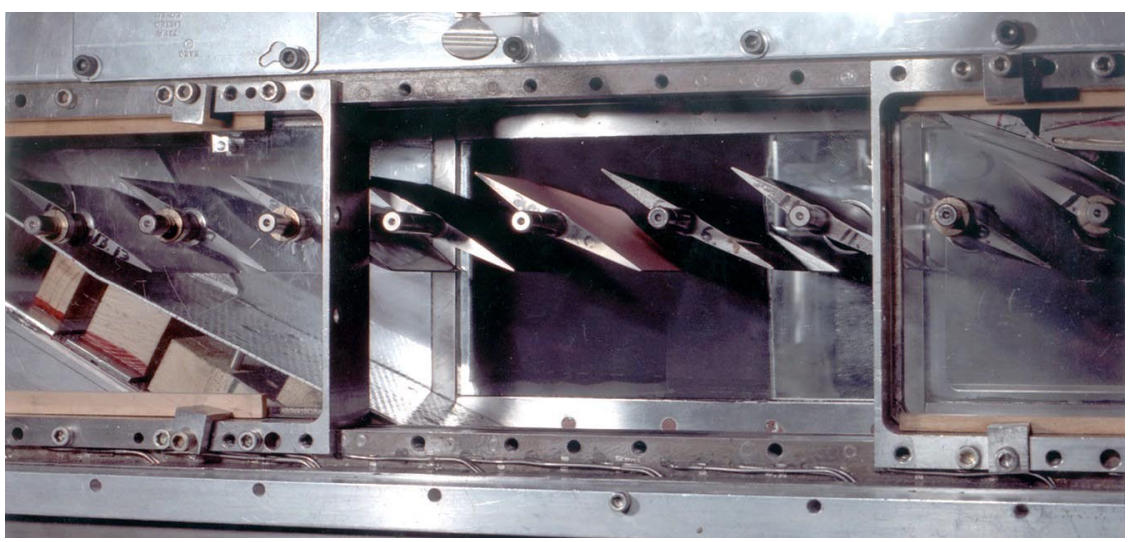

Fig. 1 Test section of the NASA Transonic Flutter Cascade. nine blades. A view of the cascade test section is in Fig. 1. Blades in the cascade can be oscillated to simulate blade flutter motion. The facility is continuously upgraded and modified to improve reliability and quality of the acquired experimental data. Previous measurements in this facility (Refs. 1 and 2) were primarily for the subsonic inlet Mach numbers of 0.5 and 0.8. Experimental blade-surface pressure distributions for steady flow showed good agreement with CFD predictions up to $85 \%$ of the blade chord only for a geometry incidence angle of $0 \mathrm{dg}$. It was argued that poor overall inlet flow uniformity and blade-to-blade flow periodicity were the cause for the discrepancy between the data and computations at operating conditions with large incidence. Consequently, the configuration of the TFC facility was modified to improve the flow periodicity in the cascade (Ref. 3). Due to the new configuration of the tunnel endwalls several discrepancies in the older data sets were resolved, particularly the questions of actual flow incidence angles and the inconsistency between predicted and measured backpressure levels.

All or any single blade in the cascade can be oscillated pitchwise to simulate torsional stall flutter conditions. Originally, all nine blades were oscillated simultaneously. However, it was observed that the oscillating cascade produced waves, which for some interblade phase angles reflected off the wind tunnel walls back into the cascade and contaminated the cascade unsteady aerodynamic data (Ref. 10). To overcome this difficulty the tunnel was provided with perforated walls and acoustic treatment at several locations. The efficiency of this modification, however, was not verified.

In addition to the contamination mentioned above, the unsteady data acquired even for no blade oscillations exhibited 'noise' in the frequency range below $150 \mathrm{~Hz}$. It was believed that this contamination was due to antenna effects of long cables between the blades that were instrumented with Kulite transducers and signal amplifiers. For safety reasons, the bank of amplifiers had to be located in the control room $12 \mathrm{~m}$ from the cascade facility. Consequently, the millivolt-level transducer signals carried on these cables were susceptible to electromagnetic contamination, even though the signal cables were carefully shielded (Ref. 9). To rectify this problem, the facility was recently equipped with a new unsteady data acquisition system that is fully computerized and the amplifiers are now located next to the cascade facility.

The frequency response of a bare transducer is stated to be flat up to $100 \mathrm{kHz}$. However, the mounting of the transducers in the blade and the RTV coating used to protect the sensing surfaces is expected to reduce the transducer frequency response. To quantify the frequency response of the installed transducers an acoustic driven resonant tube assembly analogous to that 
described in Ref.11 was used. Results from this test indicated that the response of the blade transducers were flat to frequencies over $1.0 \mathrm{kHz}$ within $\pm 2 \%$ in amplitude and $\pm 3 \mathrm{dg}$ in phase. This dynamic calibration was done on one suction surface instrumented blade and one pressure surface instrumented blade. The two additional blades have the same transducer locations as the blades tested, and therefore it is expected that the dynamic response of those blades is similar (Ref.12).

\section{NATURE OF BLADE SURFACE UNSTEADY PRESSURE DATA}

A previously reported set of experimental data (Ref. 6) is used here to illustrate the nature of unsteady pressures acquired on blade surfaces for various inlet Mach numbers and blade oscillation frequencies. Examples shown are for a transducer at port SS15, which is flush mounted along the midspan of the suction surface at the trailing edge of blade BL4 (Fig. 2). The instrumented blade is just to the left of blade BL5, which was oscillated at amplitude of $0.6 \mathrm{dg}$. Segments of $50 \mathrm{~ms}$ long

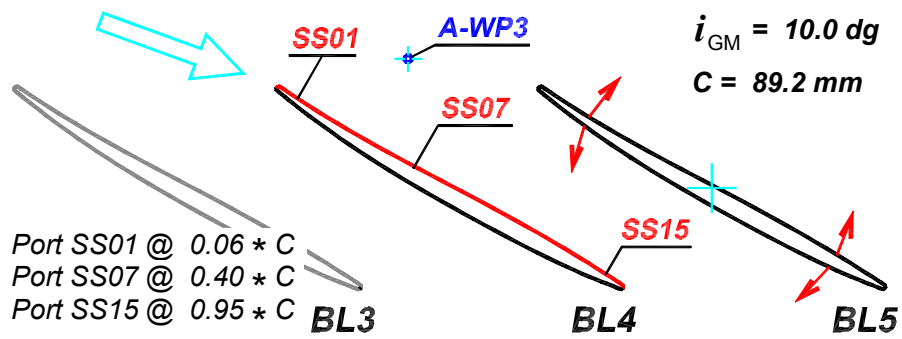

Fig. 2 Location of Kulite transducers on the suction side Of blade BL4 and the tunnel wall (A-WP3).

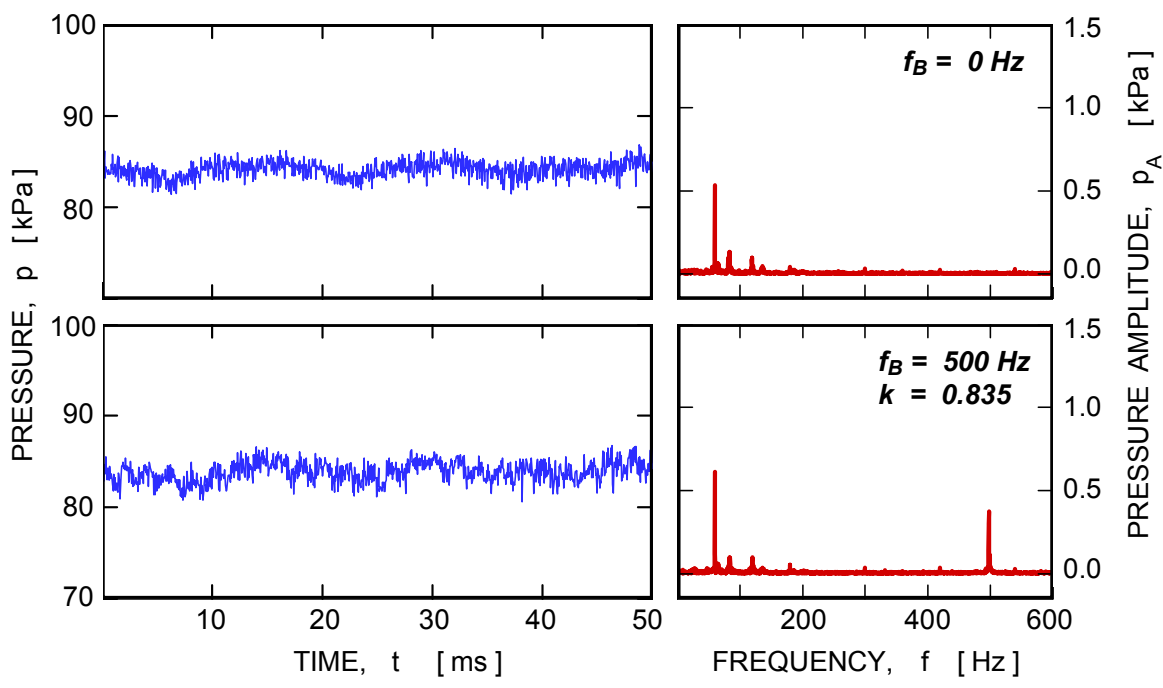

Fig. 3 Blade surface unsteady pressure data for an inlet Mach number of 0.50 , blade BL4, suction surface, port SS15. pressure data for cases of no blade oscillation and blade BL5 oscillation at $500 \mathrm{~Hz}$ for an inlet Mach number of 0.5 are shown in the left hand side of Fig. 3. Accompanying spectra are shown in the right hand side of the same figure. The plots present amplitude peak spectra computed using an FFT procedure. The spectra are not corrected for frequency leakage that often decreases amplitude levels. Both spectra show large amplitude peaks at $60 \mathrm{~Hz}$, most likely contamination due to the power net interference. While the signal cables were grounded and shielded, they extend over a long distance making the low voltage signals susceptible to this type of noise. Two local peaks in the spectrum, at about $90 \mathrm{~Hz}$ and $110 \mathrm{~Hz}$, indicate data contamination due to tunnel self-induced oscillations. For the case when the middle blade was oscillated, the effects of forced oscillations are clearly visible in the spectrum (amplitude peak at $500 \mathrm{~Hz}$ ). The amplitude of forced oscillations is an order of magnitude larger than the amplitudes of self-induced oscillations, and therefore the effects of self-induced oscillations can be ignored in this case. Of course the contamination due to the power net interference is not coming from the flow unsteadiness and can be filtered out.

The situation for the high subsonic inlet Mach number of 0.8 is noticeably different, as shown in Fig. 4. The signal for no blade oscillations exhibits very strong periodic self-induced pressure fluctuations with a peak-to-peak variation of up to $10 \mathrm{kPa}$. The spectrum shows that a large pressure fluctuation exists at $110 \mathrm{~Hz}$ with smaller second and third harmonics of this fundamental frequency. There are also side lobes visible at $90 \mathrm{~Hz}$ and $130 \mathrm{~Hz}$. In addition, the net contamination at $60 \mathrm{~Hz}$ is also visible. For the case when the middle blade was oscillated, a modulation that was superimposed on the signal is demonstrated as an amplitude peak at $500 \mathrm{~Hz}$. In this case the effects of self-induced oscillations cannot be ignored, because their amplitude is more than double of the magnitude of forced oscillations. Finally, data for the highest inlet Mach number of 1.08 are shown in Fig. 5. The pressure signal for no blade oscillations exhibits only contamination due to power net interference. There is no trace of any self-induced oscillations similar to the previous case. The pressure signal acquired with the middle blade oscillating at $400 \mathrm{~Hz}$ shows very strong modulation. The origin of the small local peak at $260 \mathrm{~Hz}$ is not obvious.

The dramatic difference in the character of unsteady pressure data for the low subsonic and supersonic inlet Mach numbers on one hand, and the high subsonic inlet Mach number with strong self-induced oscillations on the other hand has been a topic for many discussions. The origin of the strong self-induced oscillations was not clear, and it was speculated that it is either caused by instabilities in the blade separated flow 


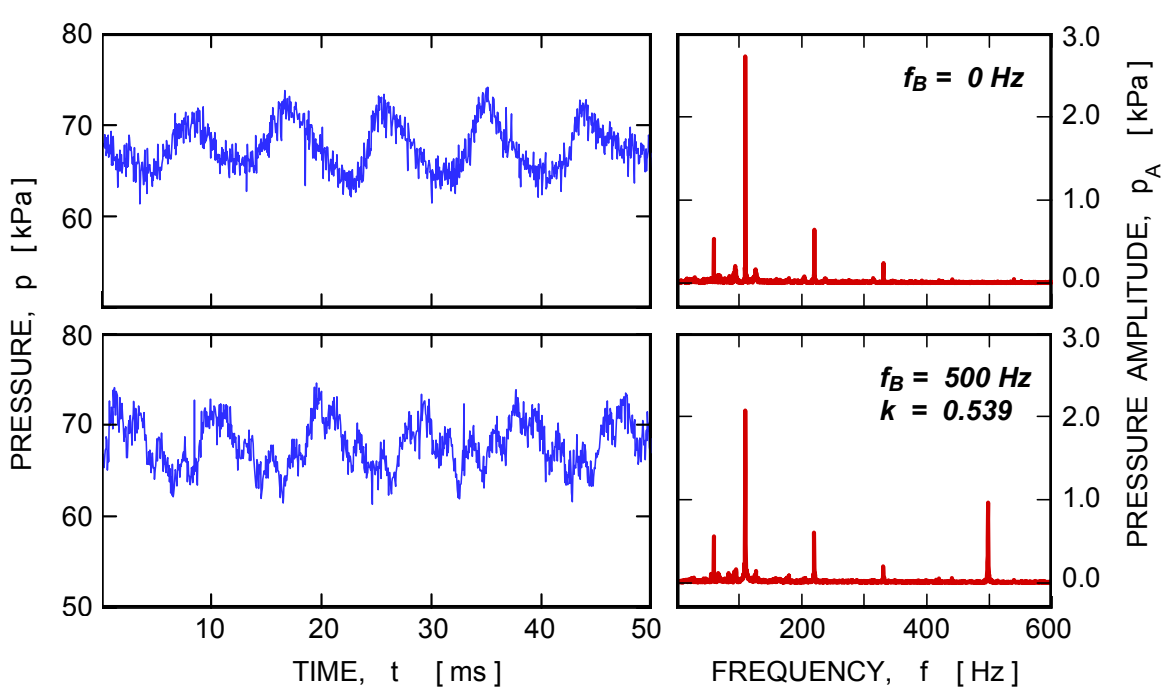

Fig. 4 Blade surface unsteady pressure data for an inlet Mach number of 0.80 , blade BL4, suction surface, port SS15.

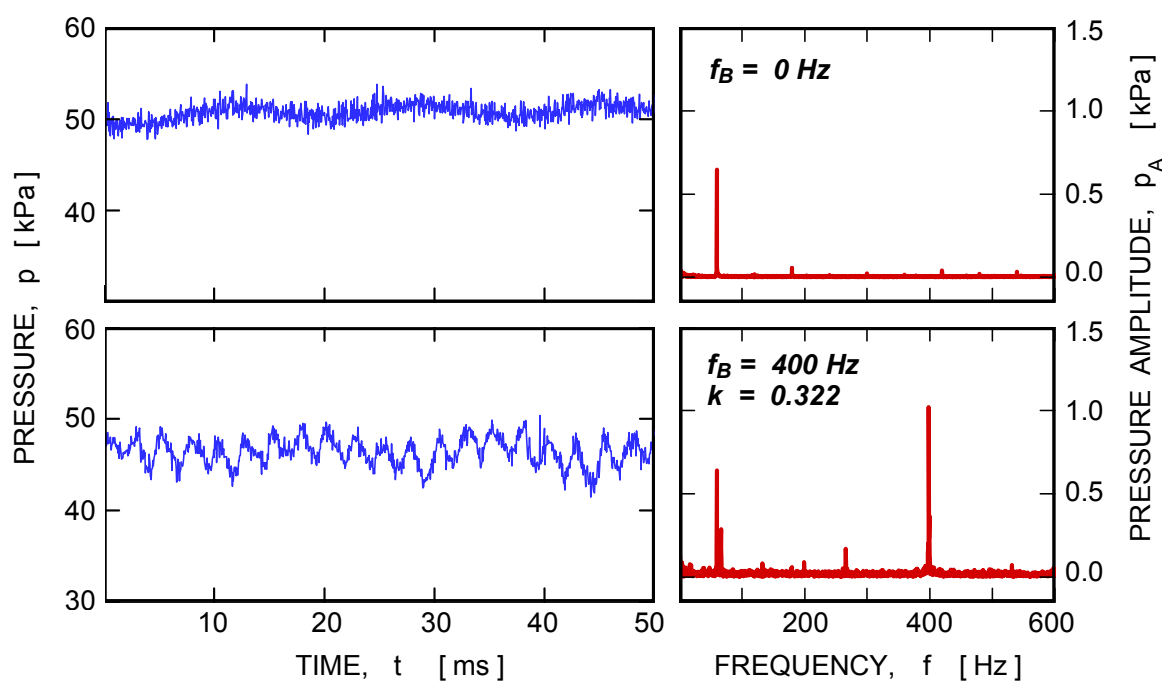

Fig. 5 Blade surface unsteady pressure data for an inlet Mach number of 1.08 , blade BL4, suction surface, port SS15.

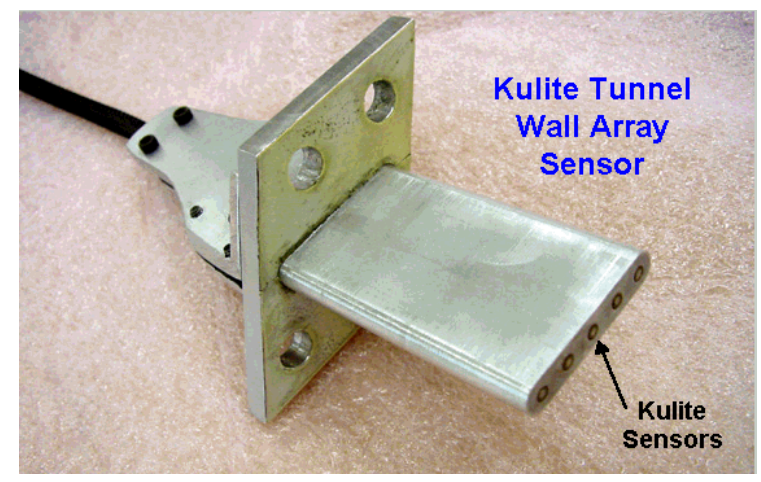

Fig. 6. Plug-in-wall unsteady pressure probe.

zone or that it is a tunnel resonance phenomenon. The cascade is operated far from the design conditions; it was demonstrated that for subsonic inlet velocities and very high incidence the separated flow zone on the blade suction side extends from the leading edge to $50 \%$ of the blade chord (Ref. 4). However, the flow separation zone for an inlet Mach number of 0.8 is only marginally larger than for a Mach number of 0.5. It seemed doubtful that small changes in the size of the separation zone as the inlet Mach number increases would cause large changes in the pressure unsteadiness as seen in Figs. 3 and 4 ; thus, the attention was focused on tunnel resonance characteristics.

\section{TUNNEL WALL UNSTEADY PRESSURES}

In the past, all unsteady instrumentation was located only on the blades, and no data was available about pressure unsteadiness in an empty tunnel. To prove that the observed phenomenon was associated with the tunnel unsteady behavior, it was necessary to instrument the tunnel wall with unsteady pressure transducers. A new probe that contains an array of five miniature pressure transducers was built. The probe, shown Fig. 6 , can be inserted in the tunnel wall at four locations, either at the cascade leading edge or trailing edge station. The transducer array can be oriented in the flow direction or perpendicular to it. Data presented in this paper is for the middle sensor for the probe located in the leading edge region (Fig. 7). The location of this sensor is shown in Fig. 2 (A-WP3).

The first run with the wall probe and the empty tunnel immediately proved beyond any doubt that the self-induced low frequency oscillations are a tunnel phenomenon, probably some kind of tunnel resonance. The presence of the blades in the tunnel has no noticeable effect on the flow pressure unsteadiness. For an inlet Mach number of 0.8 , the tunnel with blades and an empty tunnel exhibit self-induced pressure oscillations with the same frequency of about $110 \mathrm{~Hz}$, as shown in Fig. 8. This data was taken using the new data acquisition system. Absence of a local peak at $60 \mathrm{~Hz}$ indicates that the new system effectively prevents power net interference.

In order to trace the source of tunnel oscillations, tests were conducted at various inlet Mach numbers for an empty tunnel, as well as for the tunnel with the blade cascade. All data discussed in this section are for the tunnel with blades but no forced oscillations. The data is for the probe middle port while the probe was in position 'A'. Several parameters were reduced from the unsteady pressure data. First, the pressure 


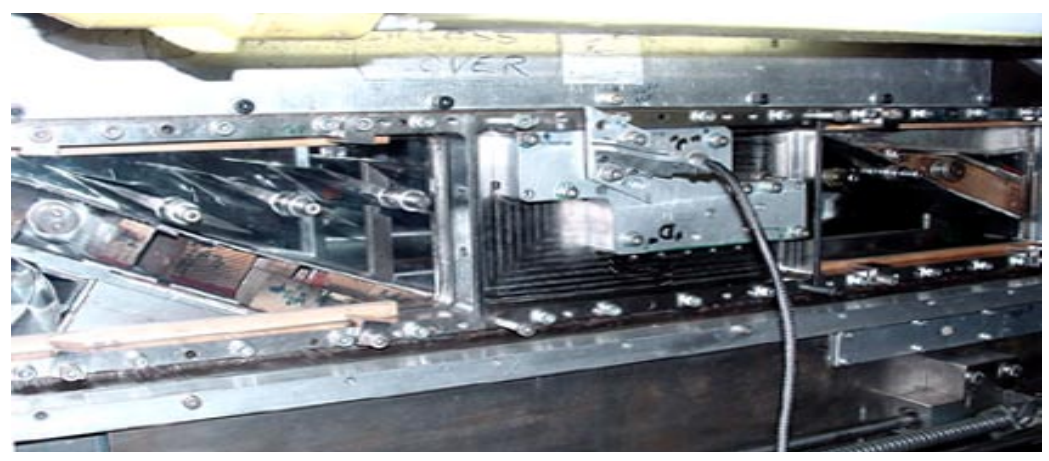

Fig. 7. Wall probe at station $A$ on the tunnel wall.

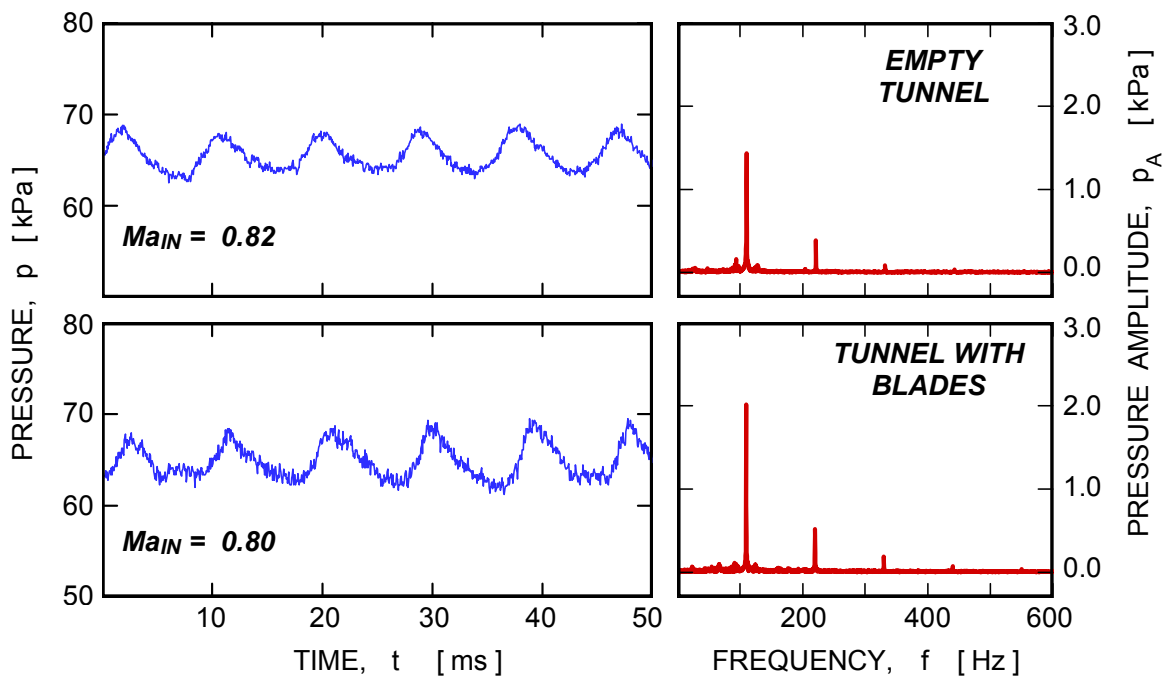

Fig. 8 Pressure oscillations in an empty tunnel and tunnel with blades.

signal root-mean-square (RMS) value of the entire data record was computed. Second, the fundamental frequency and the associated amplitude were determined from spectral analysis of each data set. Spectra for six inlet Mach numbers are shown in Fig. 9. It should be noticed that as the inlet Mach number increases, the fundamental frequency shifts stepwise from about $90 \mathrm{~Hz}$, to $110 \mathrm{~Hz}$, and to $130 \mathrm{~Hz}$. Actually small local peaks at these frequencies can be seen for most of the inlet Mach numbers. These are not harmonics but independent pressure waves.

The results of this experiment are summarized in Fig. 10. In the top diagram, the pressure RMS values and pressure unsteadiness are plotted. The pressure unsteadiness is shown as percentage value of a particular dynamic pressure. As seen here, both parameters showed an increased level for inlet Mach numbers ranging from 0.6 to 1.0. In the middle diagram, the detected fundamental frequencies of pressure fluctuations are shown as functions of the tunnel inlet Mach number. It appears that the frequency of pressure fluctuations stays just about the same for a certain range of inlet Mach numbers, and then jumps to a higher 'stage'. Finally, in the lowest diagram, the amplitudes of pressure fluctuations are presented. As seen here, each stage-amplitude rises, reaches a peak in the middle of its associated frequency range, and then decays. This behavior strongly resembles jet impingement tone behavior, (hence the use of the term 'stage'), in which stage frequency jumps are conditioned by an integer number of half wavelengths that must fit in a controlling distance (Ref. 13). This behavior
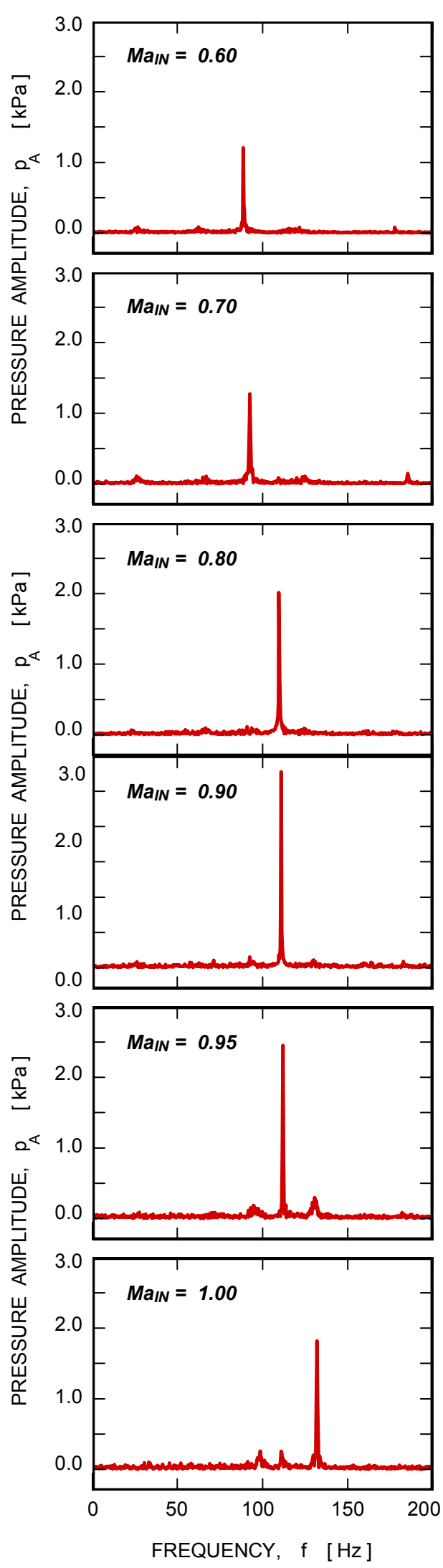

Fig. 9. Effects of inlet Mach number on frequency spectra of self-induced oscillations in tunnel with blades. 
indicated that there must be an element in the TFC facility system that acts in a similar way and generates pressure oscillations based on its acoustic characteristics.
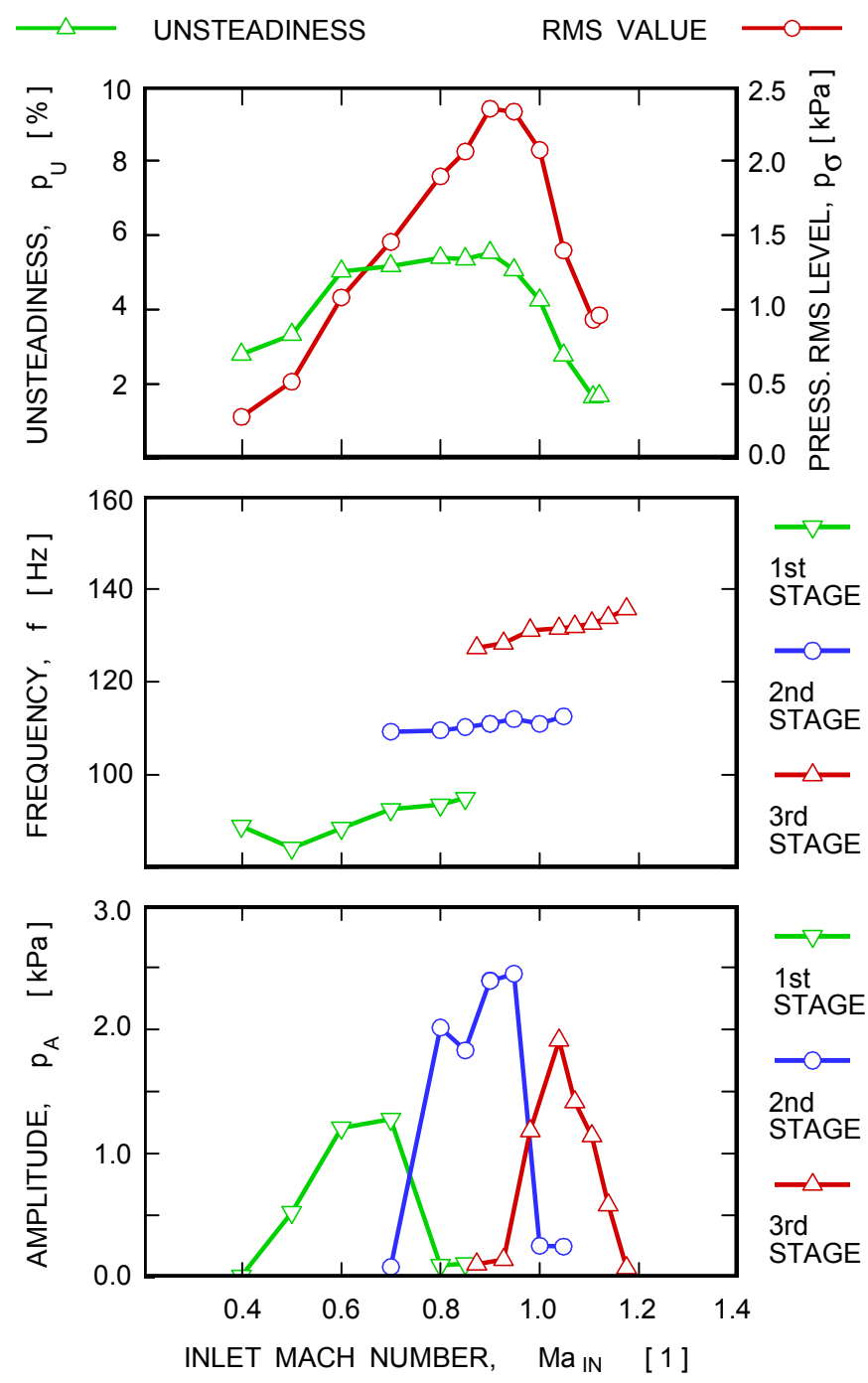

Fig. 10 Frequency analysis of unsteady pressures in tunnel with blades.

\section{EXIT DUCT RESONATORS}

The working section of the TFC facility was carefully inspected for any possible source of pressure fluctuations. Even access holes and slits for probe traversing, upstream and downstream of the cascade, were covered; however, no changes in the tunnel behavior were observed. Finally, the entire duct system that connects the cascade facility with the NASA central exhaust system was inspected and several potential resonators were found. The layout of the entire TFC system is depicted in Fig. 11 and a photograph is in Fig. 12. As seen here, there are several tubes attached to the main duct (labeled R1 through R5) that serve either as attachment points for other facilities or compensatory elements to lower noise level in the central duct. These elements are located past the long transitional duct that converts flow area from a rectangular one with a high aspect ratio to a circular crosssectional area. The overall area ratio between the end of the transitional duct and the cascade flow area is 16.5. These elements, or at least some of them, were found to be the source of the tunnel resonant behavior. The elements R1 through R3 are welded to the main duct. Elements R4 and R5 have attachment flanges; the original arrangement is labeled R4a and R5a in Fig. 11, and the reduced length elements are marked by $\mathrm{R} 4 \mathrm{~b}$ and R5b. Reduction in length of elements R4 and R5 did not bring any noticeable change in the tunnel behavior. Element R1 is provided with a piston inside that can be repositioned to vary the tube length as also indicated in Fig. 11. This element proved to be the crucial resonator that controls the behavior of the entire system. It is ironic that it was probably built for this purpose originally, but was not used for at least the last 15 years and no report was found that would indicate its role.

An effect of the resonator R1 on the level of pressure unsteadiness is illustrated in Fig. 13 for two resonator settings. As seen here, correct resonator tuning significantly suppresses the self-induced oscillations. Even though the frequency content is similar, the amplitude of pressure oscillations was reduced by an order of magnitude. Spectral characteristics of tunnel oscillations for the entire tunable range of resonator R1 are summarized for an inlet Mach number of 0.8 is Fig. 14 . Tuning can drop the overall pressure unsteadiness $\left(p_{U}\right)$ from about $4.5 \%$ down to $2.0 \%$. As the lowest diagram in Fig. 14 reveals, this drop is mainly due to the suppression of the stage-2 oscillations $(110 \mathrm{~Hz})$, while the other two stages show an increase in their amplitudes for the same tuning range. Because the oscillation damping depends on the inlet Mach number, the resonator R1 must be tuned for each inlet Mach number above the value of 0.5 .

\section{EFFECTS ON FORCED BLADE OSCILLATIONS}

The results discussed above revealed the source of the selfexcited oscillations in the GRC TFC facility. It was also shown, that these oscillations could be suppressed to a large extent by changing the length of the R1 resonator. It is obvious now that for future testing the facility must be tuned for minimum level of self-induced oscillations for each inlet Mach number before the flutter experiments are carried out.

A considerable amount of flutter simulation data has been acquired in this facility to date, and therefore major questions now are to what extent are the previously acquired data contaminated by the tunnel self-excited oscillations, and whether these data truly represent the unsteady flow behavior in a transonic fan under real flutter conditions. To answer 


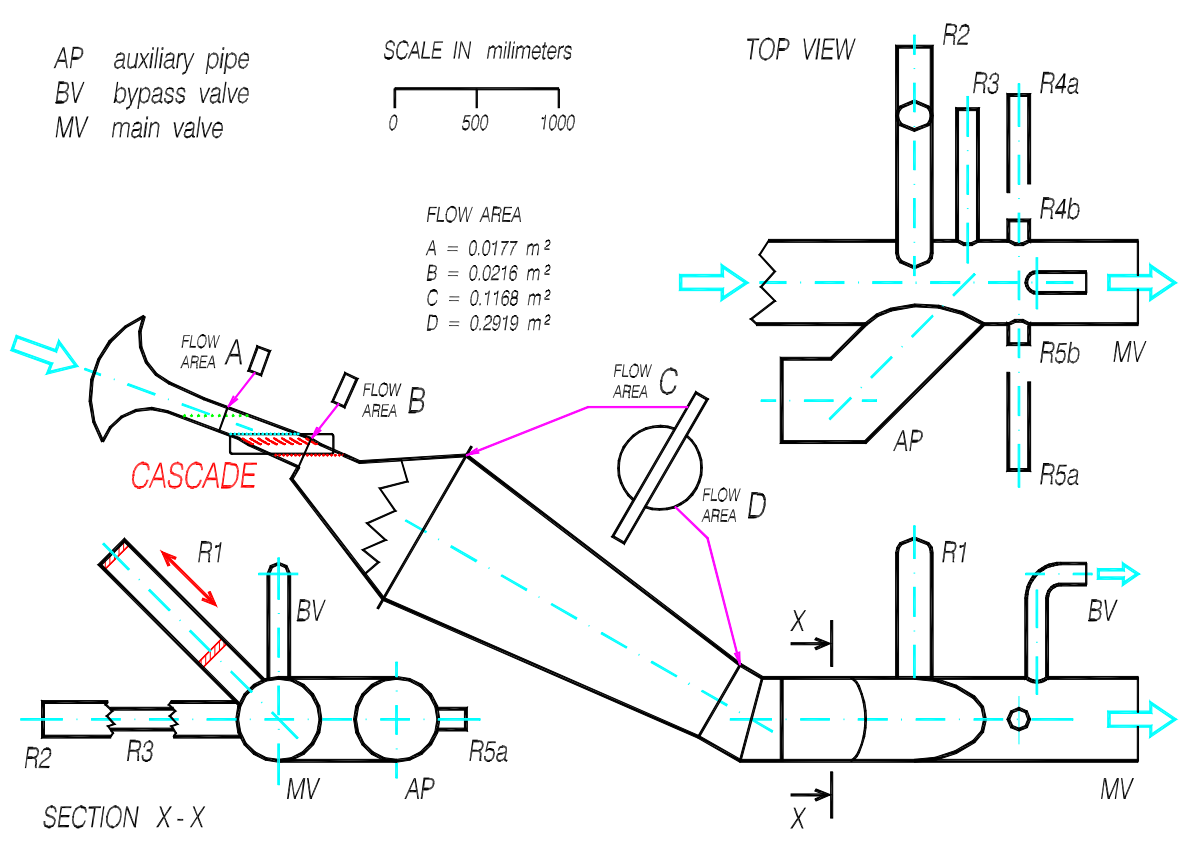

Fig. 11. Layout of NASA GRC Transonic Flutter Cascade Facility.

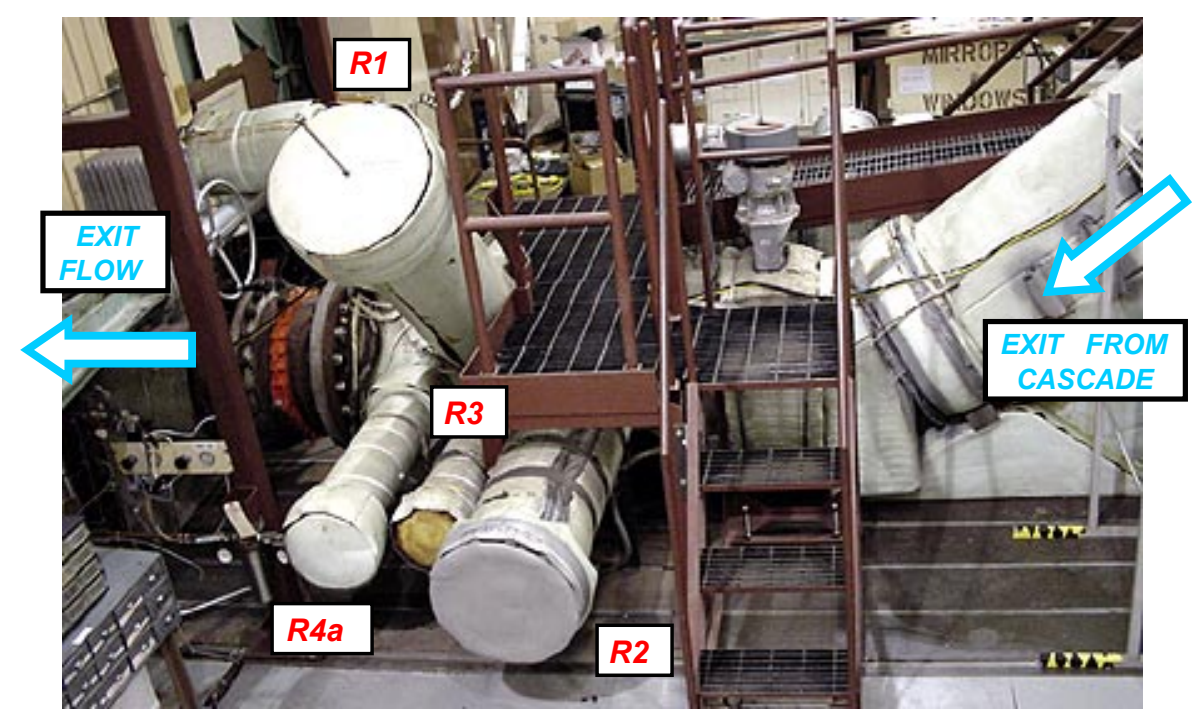

Fig. 12. View of exit duct resonators.

these questions, at least qualitatively, two new sets of data were acquired. The data were acquired in a nearly identical manner as the data in Refs. 5, 6, and 9. The only difference is that the amplitude of the middle blade oscillations is now $1.2 \mathrm{dg}$ instead of 0.6.dg. The reason for this is that the facility is now reconfigured to use the cam with the larger blade oscillation amplitude, and facility reconfigurations are very costly.

For the first new data set, the tunnel was operated with resonator $\mathrm{R} 1$ set for the maximum length of $R 1_{L}=356 \mathrm{~mm}$, for which the self-induced oscillations in the tunnel are maximum (Fig. 13, upper diagram). The second set of data was acquired for the resonator setting at $R l_{L}=673 \mathrm{~mm}$, for which the maximum suppression of the self-induced oscillations was achieved (Fig. 13, lower diagram). The middle blade BL5 was oscillated for a range of frequencies at both settings of resonator R1. The results are presented in Figs. 15 and 16.

Data in both figures show segments of 50-ms long pressure data in the left hand side and corresponding spectra in the right hand side of the figure. The spectra were calculated for the entire data set of 3000-ms long segments (120000 data points). The spectral amplitude values are not corrected for frequency leakage. Five sets of diagrams in each figure show cases for no middle blade oscillation, as well as for blade oscillations of $200 \mathrm{~Hz}, 300 \mathrm{~Hz}$, $400 \mathrm{~Hz}$, and $500 \mathrm{~Hz}$. For the case of the mistuned tunnel (Fig. 15), all spectra clearly show a frequency peak at $110 \mathrm{~Hz}$, which is the first harmonic of the selfinduced oscillations, as well as peaks of decreasing amplitude for the second and third harmonics $(220 \mathrm{~Hz}$ and $330 \mathrm{~Hz}$, respectively). Presence of the second and third harmonics indicate that the waveform of the self-induced oscillations differ from a sine wave as can be seen clearly in the data segment for no blade oscillation (Fig. 15). A frequency peak for the forced oscillations is also clearly visible in the spectra for each of the middle blade oscillation frequencies. The spectra do not indicate presence of higher harmonics of the forced oscillations, which indicates pure sine wave character of the forced motion. For the case when the tunnel was tuned to suppress the self-induced oscillations, the forced motion clearly dominates the spectra as seen in Fig. 16.

The results of spectral analysis are summarized in Figs. 17 through 19, where amplitudes for the first three harmonics of self-induced oscillations and the amplitude of the first harmonic for the forced oscillations are plotted as functions of the forced frequency for mistuned and tuned tunnel conditions. There are two sets of data in these figures. One set presents uncorrected spectral amplitude levels as retrieved from spectra of Figs. 15 and 16. The other set presents amplitude levels corrected for frequency leakage in FFT data (forced oscillations only). The artifact of frequency leakage (Ref. 14) is due to finite data acquisition scanning rate and to small variations in blade oscillation frequency during data acquisition interval of $3 s$. Both of these factors broaden the amplitude peak over a few adjacent bins in the frequency domain, which consequently 


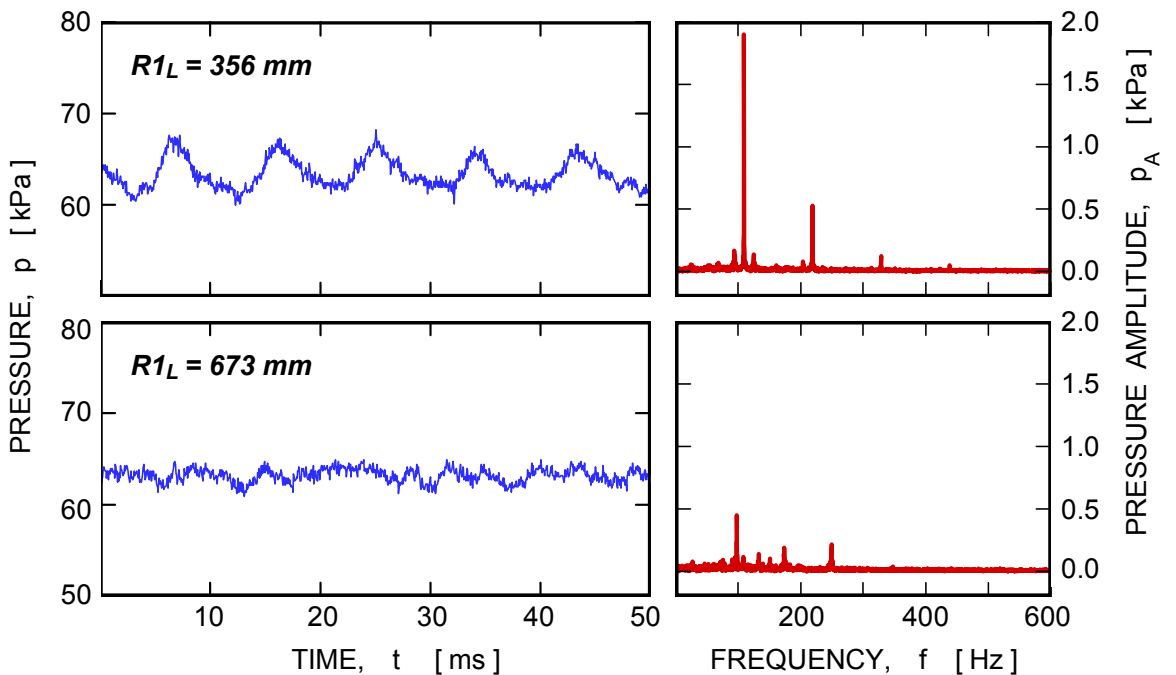

Fig. 13 Tunnel wall unsteady pressures for an inlet Mach number of $\mathbf{0 . 8 0}$ and two settings of resonator R1.
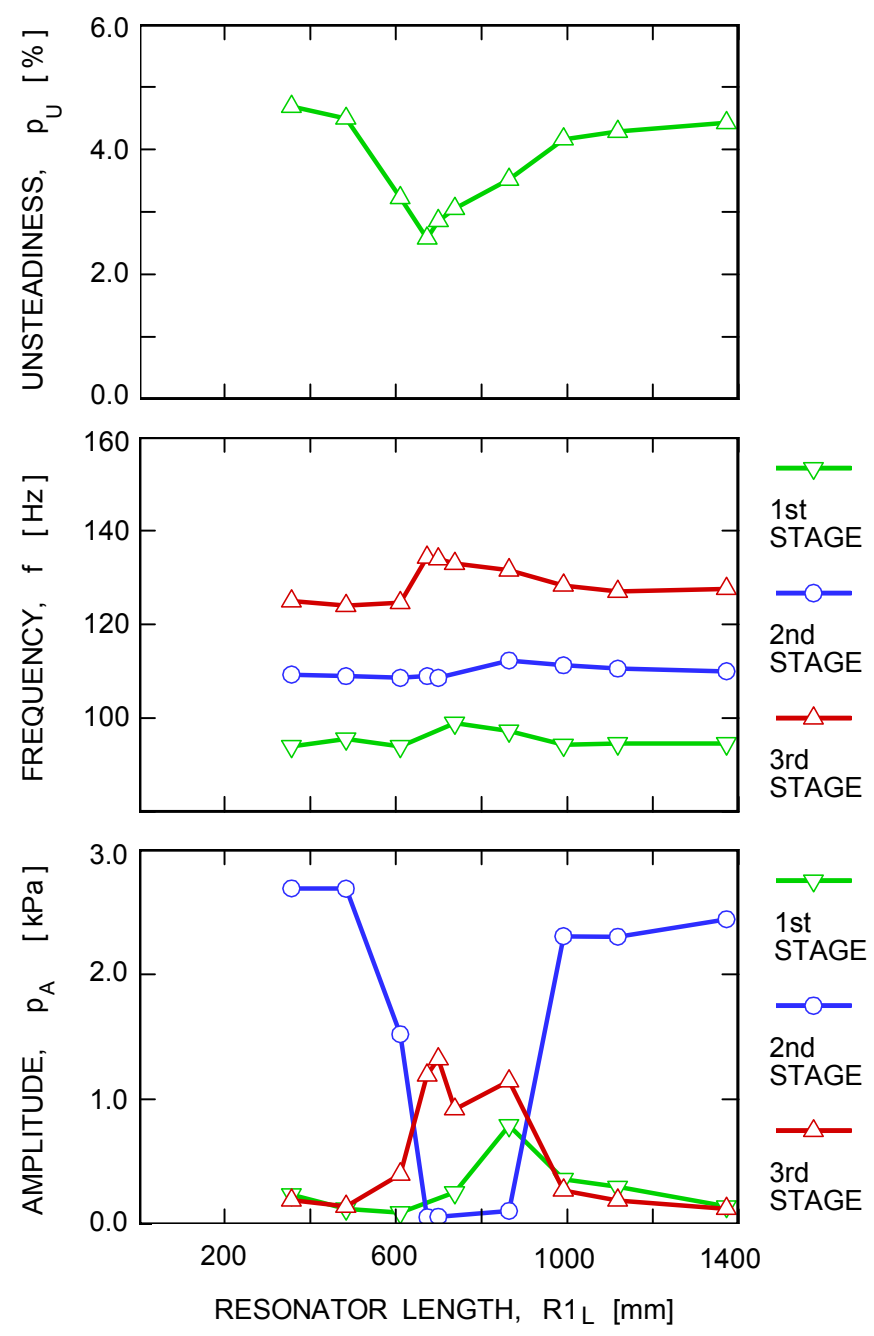

Fig. 14 Effects of resonator length on tunnel spectral characteristics for an inlet Mach number of 0.80 . lowers the maximum amplitude value. Frequency leakage problems arise from slight variations in the frequency of forced blade oscillations during the measurement interval. To correct this problem, each data set was subdivided into blocks consisting of 30 oscillation blade cycles. Then, each data block was analyzed separately using the FFT procedure. Finally, the resulting amplitude was determined by averaging the amplitudes from each data block.

As seen in Figs. 17 and 18, the forcing frequency has a negligible effect on the harmonic amplitudes of the self-induced oscillations. Only the first harmonic is shown for the tuned tunnel (Fig. 18) because the amplitudes of higher order are very small. However, the uncorrected forced amplitude values, in Figs. 17 and 18, show large scatter with forcing frequency, while the corrected amplitude data show no changes. This clearly illustrates the importance of frequency leakage corrections of FFT data. Based on the corrected data, it is concluded that the forcing frequency has no effect on the amplitude of forced oscillations on the tunnel wall. Further, the level of forced oscillation amplitude for the tuned tunnel is equal to the level for the mistuned tunnel, therefore, it follows that there is no coupling between the self-induced and forced oscillations. Oscillations on the suction side of blade BL4 are shown in Fig. 19. First, the level of forced oscillations is much lower, because of the smaller amplitude of blade oscillations $(0.6 \mathrm{dg})$. Second, the level of corrected forced pressure oscillation increases with frequency. This agrees with findings for an inlet Mach number of 0.5 , when self induced oscillations are negligible (Ref. 6).

Another way to extract information about the blade forced oscillation response, particularly about the waveform, is to subject the data sets to ensemble averaging procedures. Spectral analysis cannot supply such information. Ensemble averaging reduces the random pressure fluctuations, but preserves the periodic content of the signal that is locked to the basis of averaging; it is to the frequency of blade oscillations in our case. Therefore, not only random fluctuations but also periodic changes in the signal history that are not phase-locked to the frequency of blade oscillations, like self-induced oscillations, will be suppressed. Fig. 20 presents an example of the time basis signal for ensemble averaging, and the pressure history signal. The upper trace is a record of a proximity capacity sensor that faces a cam on the drive shaft of the blade oscillating mechanism. The blade oscillation is forced by rotation of this camshaft. Therefore, there is a fixed relationship between the amplitude of this signal and blade angular position. Figures 21 and 22 show the results of ensemble averaging for the wall probe for mistuned and tuned tunnel and for the inlet Mach number of 0.8 . The case for blade oscillation frequency of $200 \mathrm{~Hz}$ is depicted in Fig. 21, and the case for $500 \mathrm{~Hz}$ in Fig. 22. The diagrams in the 
MISTUNED TUNNEL $\left(R 1_{L}=356 \mathrm{~mm}\right)$
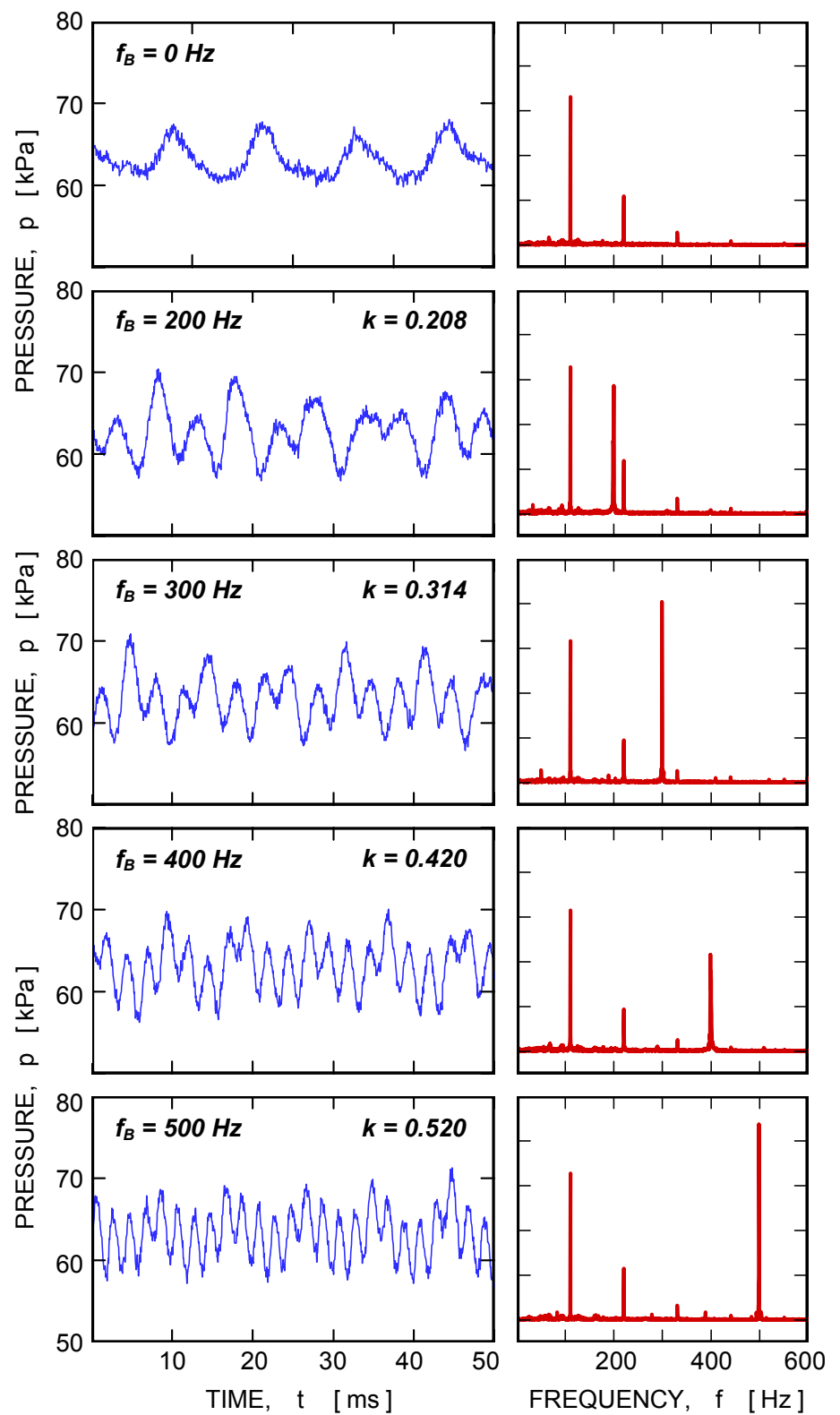

Fig. 15 Effects of forced oscillations on unsteady pressures measured on a tunnel wall for an inlet Mach number of $\mathbf{0 . 8 0}$ and mistuned tunnel.

upper row in both figures show the waveform of the forced pressure signal for one period of blade oscillation, while the diagrams in the lower row show RMS average values of the forced pressure signal. As seen in these figures, the waveform of the forced signal does not differ significantly for frequencies of $200 \mathrm{~Hz}$ and $500 \mathrm{~Hz}$. For the case of $200 \mathrm{~Hz}$ (Fig. 21) the waveform seems to be pure sinusoidal, while for the high frequency of $500 \mathrm{~Hz}$ (Fig. 22) the form is slightly distorted, which indicates that it also contains higher harmonics. In both cases, however, the maximum signal deviation from an average value is the same, about $3.1 \mathrm{kPa}$, which agrees extremely well with the corrected amplitude
TUNED TUNNEL $\left(R 1_{L}=673 \mathrm{~mm}\right)$

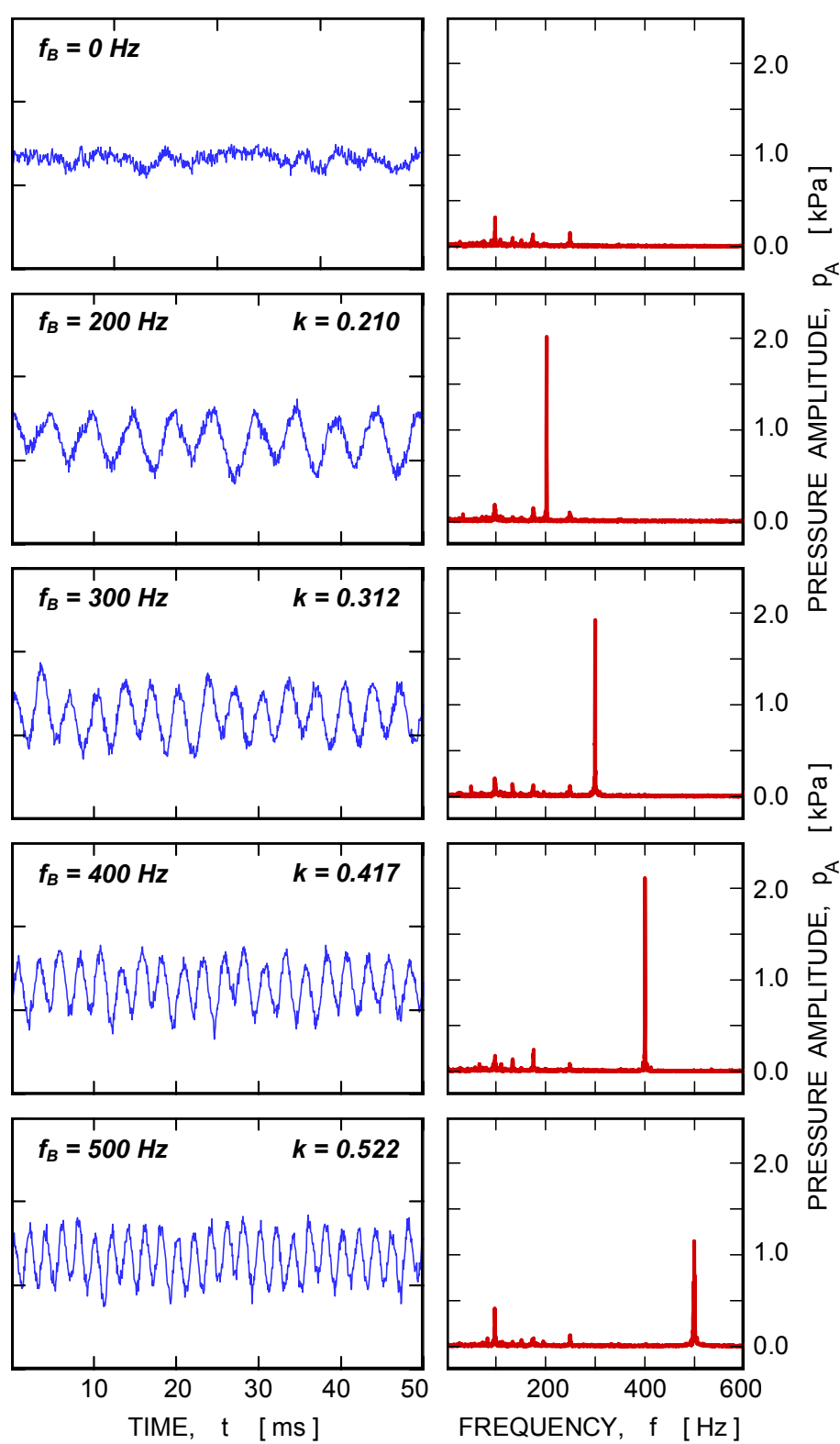

Fig. 16 Effects of forced oscillations on unsteady pressures measured on a tunnel wall for an inlet Mach number of $\mathbf{0 . 8 0}$ and tuned tunnel.

values determined from frequency analysis (Figs. 17 and 19). Finally, the level of pressure unsteadiness (RMS values) for the mistuned tunnel is about twice that for the tuned tunnel. In summary, the results of ensemble averaging confirm the findings based on spectral analysis. The interaction between self-induced oscillations and forced modulation is very weak and generally it can be neglected. The frequency and the ensemble-averaged waveform, and the maximum amplitude of forced modulation are not altered at all by the presence of selfinduced oscillations. The only detrimental effect of selfinduced oscillations is that they increase scatter in the forced modulation signal from one period to another. 


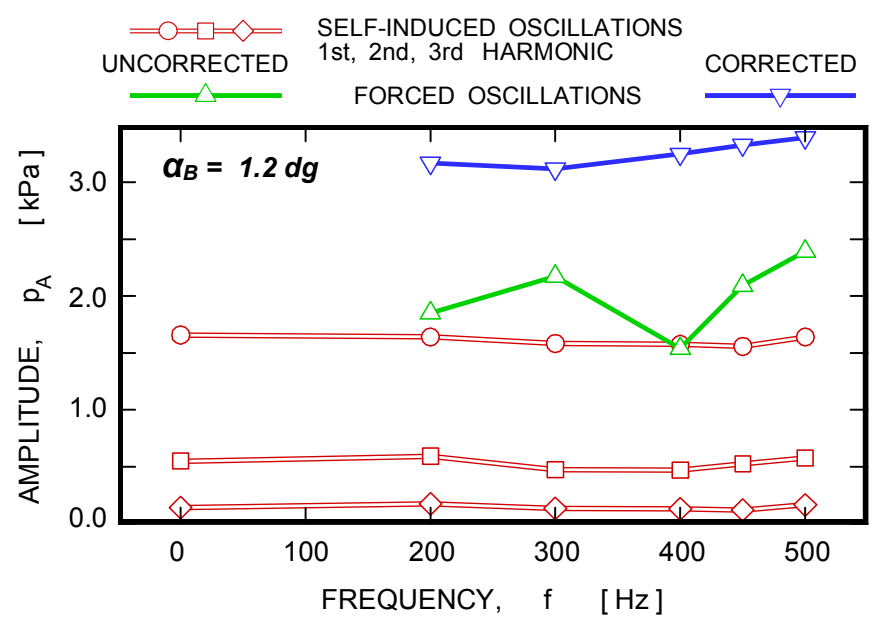

Fig. 17 Effects of blade oscillation frequency on pressure fluctuations on tunnel wall for an inlet Mach number of 0.80 and mistuned tunnel.

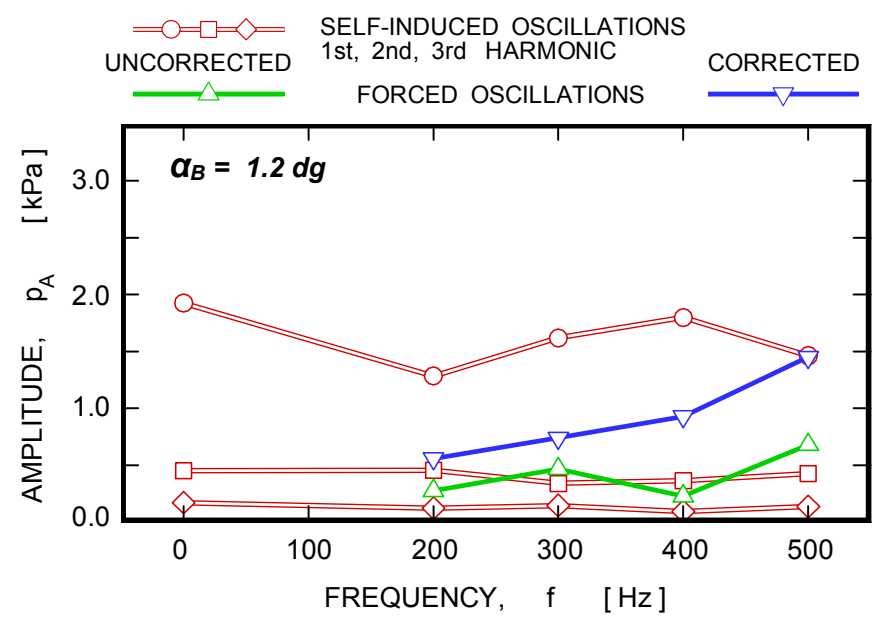

Fig. 18 Effects of blade oscillation frequency on pressure fluctuations on tunnel wall for an inlet Mach number of 0.80 and tuned tunnel.

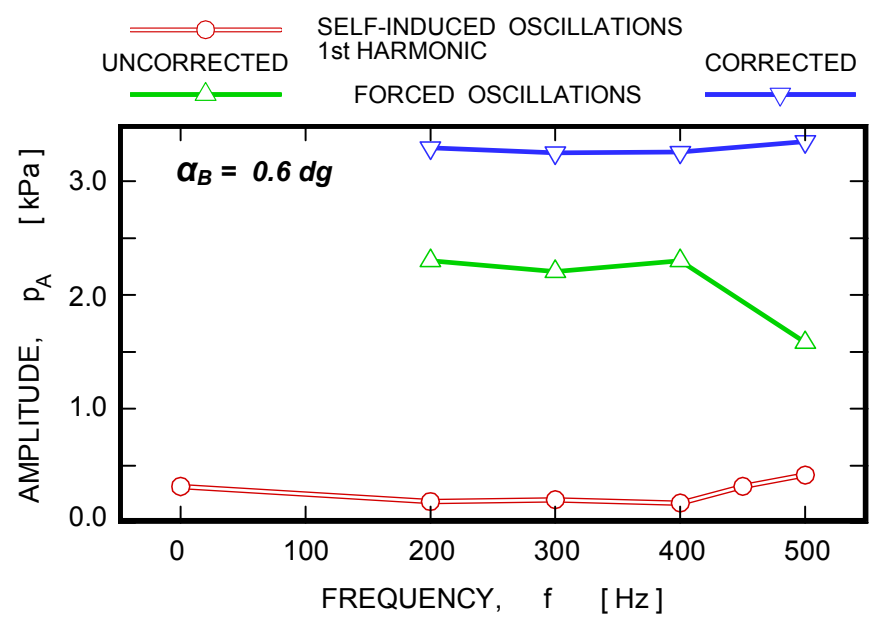

Fig. 19 Effects of blade oscillation frequency on pressure fluctuations on blade BL4 port 15 for an inlet Mach number of 0.80 and mistuned tunnel.

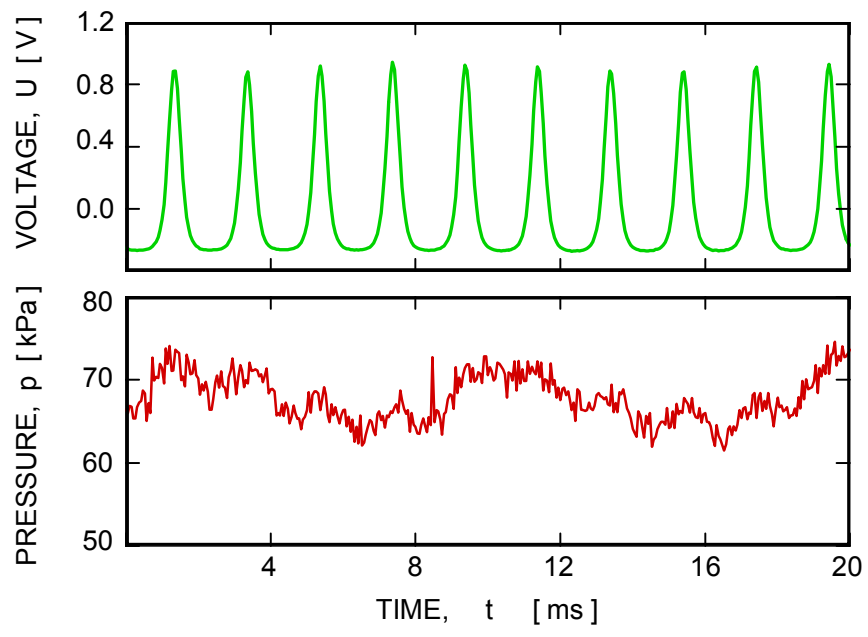

Fig. 20 Blade motion and pressure transducer signals.

\section{CONCLUSIONS}

The following conclusions can be drawn from this study:

- It was shown that strong low-frequency oscillations observed for inlet Mach numbers of about 0.8 are not a cascade phenomenon, but they are caused solely by tunnel resonance characteristics.

- Most likely, the self-induced oscillations originate in a system of exit duct resonators. It is surprising how strongly the cascade flowfield unsteadiness is affected by elements located that far downstream of the cascade.

- The level of self-induced pressure fluctuations can be significantly suppressed for a narrow range of inlet Mach numbers by tuning one of the exit duct resonators. The fluctuation level with respect to the dynamic pressure can be lowered from $4.5 \%$ to $2.5 \%$. The tunnel must be tuned for each inlet Mach number.

- Spectral and ensemble averaging analyses showed that the interaction between self-induced oscillations and blade forced oscillation is very weak, and generally it can be neglected. The frequency and the ensemble-averaged waveform, and the maximum deviation of forced oscillation response are not altered at all by the presence of self-induced oscillations.

- The self-induced oscillations, however, increase the scatter in forced oscillation signal from one period to another.

- The forced oscillation data acquired for the mistuned tunnel, when strong self-induced oscillations were present, can be used as reliable forced pressure fluctuations provided that these signals are extracted from raw data sets by an ensemble averaging procedure. 


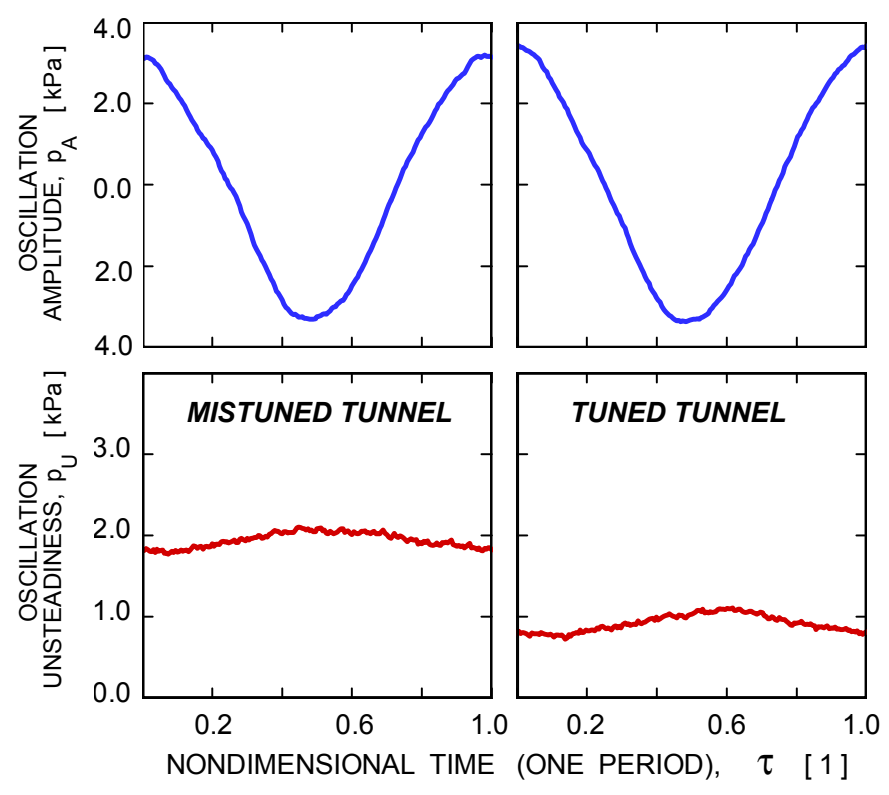

Fig. 21 Effects of tunnel tuning on forced pressure oscillation as recorded on tunnel wall for inlet Mach number of 0.8 , blade frequency $200 \mathrm{~Hz}$, and oscillation amplitude of $\mathbf{1 . 2} \mathbf{d g}$.

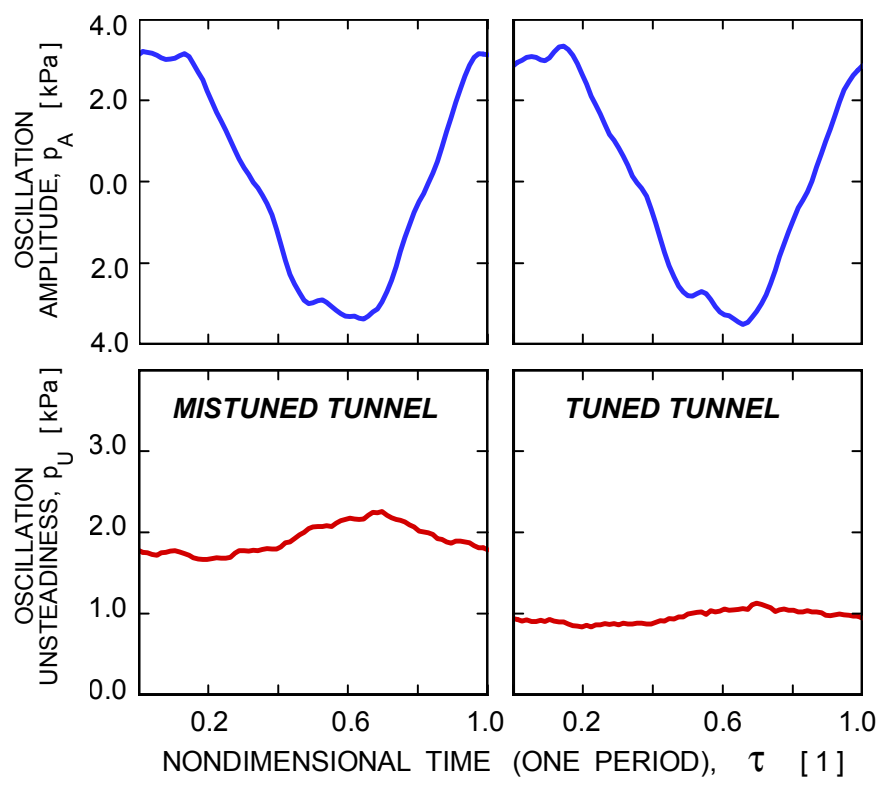

Fig. 22 Effects of tunnel tuning on forced pressure oscillation as recorded on tunnel wall for inlet Mach number of 0.8 , blade frequency $500 \mathrm{~Hz}$, and oscillation amplitude of $1.2 \mathrm{dg}$.

\section{REFERENCES}

1. Buffum, D.H., Capece, V.R., King, A.J., and El-Aini, Y.M.: "Oscillating Cascade Aerodynamics at Large Mean Incidence", ASME Paper 96-GT-339, also NASA TM107247, 1996.

2. Buffum, D.H., Capece, V.R., King, A.J., and El-Aini, Y.M.: "Experimental Investigation of Unsteady Flows at Large Incidence Angles in a Linear oscillating Cascade", AIAA Paper 96-2823, 1996, also NASA TM-107283.

3. Lepicovsky, J., McFarland, E.R., Chima, R.V., and Wood, J.R.: "On Flow Periodicity in the NASA Transonic Flutter Cascade", Journal of Turbomachinery, Vol. 123, pp. 501509, 2001.

4. Lepicovsky, J., Chima, R.V., Jett, T.A., Bencic, T.J., and Weiland, K.E.: "Investigation of Flow Separation in a Transonic-Fan Linear Cascade Using Visualization Methods", NASA/TM-2000-210521, 2000.

5. Lepicovsky, J., McFarland, E.R., Chima, R.V., Capece, V.R., and Hayden, J.: "Intermittent Flow Regimes in a Transonic Fan Airfoil Cascade", NASA TM-2002-211375, 2002.

6. Lepicovsky, J., McFarland, E.R., Capece, V.R., and Hayden, J.: "Unsteady Pressures in a Transonic Fan Cascade Due to a Single Oscillating Airfoil", ASME Paper 2002-30312, 2002.

7. Boldman, D.R. and Buggele, A.E.: "Wind Tunnel Test of Blade Subjected to Midchord Torsional Oscillations at High Subsonic Stall Flutter Conditions", NASA TM78998, 1978.

8. Shaw L.M., Boldman, D.R., Buggele, A.E., and Buffum, D.H.: "Unsteady Pressure measurements on a Biconvex Airfoil in a transonic Oscillating Cascade", Journal of Engineering for Gas Turbines and Power, Vol. 108, pp. $53-59,1986$.

9. Lepicovsky, J., McFarland, E.R., Capece, V.R., Jett, T.A., and Senyitko, R.G.: "Methodology of Blade Unsteady Pressure Measurement in the NASA Transonic Flutter Cascade", NASA TM-2002-211894, 2002.

10. Buffum, D.H. and Fleeter, S.: "Wind Tunnel Wall Effects in a Linear Oscillating Cascade", NASA TM-103690, 1991.

11. Capece, V.R. and Fleeter, S.: "Forced Response Unsteady Aerodynamics in a Multistage Compressor", Purdue University Report ME-TSPC-TR-87-12.

12. Hayden, J., Capece, V.R., and Lepicovsky, J.: "The Influence Coefficient Method for Airfoils Oscillating in Pitching Mode at Large Mean Incidence," 38th AIAA/ASME/SAE/ASEE Joint Propulsion Conference, AIAA Paper 2002-4087, 2002.

13. Lepicovsky, J. and Ahuja, K.K.: "Some New Results on Edge-Tone Oscillations in High-Speed Subsonic Jets", AIAA Paper 83-0665, 1983.

14. Burgess, J.C.: "On Digital Spectrum Analysis of Periodic Signals", Journal of Acoustical Society of America, Vol. 58, No. 3, 1975. 
Public reporting burden for this collection of information is estimated to average 1 hour per response, including the time for reviewing instructions, searching existing data sources, gathering and maintaining the data needed, and completing and reviewing the collection of information. Send comments regarding this burden estimate or any other aspect of this collection of information, including suggestions for reducing this burden, to Washington Headquarters Services, Directorate for Information Operations and Reports, 1215 Jefferson Davis Highway, Suite 1204, Arlington, VA 22202-4302, and to the Office of Management and Budget, Paperwork Reduction Project (0704-0188), Washington, DC 20503.

\begin{tabular}{|l|l|l|}
\hline 1. AGENCY USE ONLY (Leave blank) & $\begin{array}{c}\text { 2. REPORT DATE } \\
\text { August } 2003\end{array}$ & $\begin{array}{c}\text { 3. REPORT TYPE AND DATES COVERED } \\
\text { Final Contractor Report }\end{array}$ \\
\hline
\end{tabular}

\section{TITLE AND SUBTITLE} 5. FUNDING NUMBERS

Resonance Effects in the NASA Transonic Flutter Cascade Facility

\section{AUTHOR(S)}

WBS-22-708-28-04

NAG3-2695

J. Lepicovsky, V.R. Capece, and C.T. Ford

7. PERFORMING ORGANIZATION NAME(S) AND ADDRESS(ES)

8. PERFORMING ORGANIZATION REPORT NUMBER

QSS Group, Inc.

21000 Brookpark Road

Cleveland, Ohio 44135

E-13962

9. SPONSORING/MONITORING AGENCY NAME(S) AND ADDRESS(ES)

National Aeronautics and Space Administration

Washington, DC 20546-0001

10. SPONSORING/MONITORING AGENCY REPORT NUMBER

NASA CR-2003-212384

GT-2003-38344

\section{SUPPLEMENTARY NOTES}

Prepared for the Turbo Expo 2003 cosponsored by the American Society of Mechanical Engineers and the International Gas Turbine Institute, Atlanta, Georgia, June 16-19, 2003. J. Lepicovsky, QSS Group, Inc., Cleveland, Ohio 44135; V.R. Capece and C.T. Ford, University of Kentucky, Paducah, Kentucky 42002. Project Manager, Eric McFarland, Turbomachinery and Propulsion Systems Division, NASA Glenn Research Center, organization code 5810, 216-433-5915.

Unclassified - Unlimited

Subject Categories: 07 and 09

Distribution: Nonstandard

Available electronically at http://gltrs.grc.nasa.gov

This publication is available from the NASA Center for AeroSpace Information, 301-621-0390.

\section{ABSTRACT (Maximum 200 words)}

Investigations of unsteady pressure loadings on the blades of fans operating near the stall flutter boundary are carried out under simulated conditions in the NASA Transonic Flutter Cascade facility (TFC). It has been observed that for inlet Mach numbers of about 0.8 , the cascade flowfield exhibits intense low-frequency pressure oscillations. The origins of these oscillations were not clear. It was speculated that this behavior was either caused by instabilities in the blade separated flow zone or that it was a tunnel resonance phenomenon. It has now been determined that the strong low-frequency oscillations, observed in the TFC facility, are not a cascade phenomenon contributing to blade flutter, but that they are solely caused by the tunnel resonance characteristics. Most likely, the self-induced oscillations originate in the system of exit duct resonators. For sure, the self-induced oscillations can be significantly suppressed for a narrow range of inlet Mach numbers by tuning one of the resonators. A considerable amount of flutter simulation data has been acquired in this facility to date, and therefore it is of interest to know how much this tunnel self-induced flow oscillation influences the experimental data at high subsonic Mach numbers since this facility is being used to simulate flutter in transonic fans. In short, can this body of experimental data still be used reliably to verify computer codes for blade flutter and blade life predictions? To answer this question a study on resonance effects in the NASA TFC facility was carried out. The results, based on spectral and ensemble averaging analysis of the cascade data, showed that the interaction between self-induced oscillations and forced blade motion oscillations is very weak and can generally be neglected. The forced motion data acquired with the mistuned tunnel, when strong self-induced oscillations were present, can be used as reliable forced pressure fluctuations provided that they are extracted from raw data sets by an ensemble averaging procedure.

14. SUBJECT TERMS

Transonic cascade; Blade flutter; Unsteady flow 15. NUMBER OF PAGES 17

\begin{tabular}{|c|c|c|}
\hline $\begin{array}{c}\text { 17. SECURITY CLASSIFICATION } \\
\text { OF REPORT }\end{array}$ & $\begin{array}{c}\text { 18. SECURITY CLASSIFICATION } \\
\text { OF THIS PAGE }\end{array}$ & $\begin{array}{c}\text { 19. SECURITY CLASSIFICATION } \\
\text { OF ABSTRACT } \\
\text { Unclassified }\end{array}$ \\
Unclassified & Unclassified
\end{tabular}



